\title{
EFFECTS OF TEMPORAL VARIATION IN SEDIMENT REDUCTION FOLLOWING IMPROVED LAND MANAGEMENT PRACTICES ON END-OF-SYSTEM DELIVERY: A MODELLING INVESTIGATION OF A GRAZED CATCHMENT IN QUEENSLAND, AUSTRALIA
}

\author{
MELANIE E. ROBERTS ${ }^{1, *} \&$ ROBIN ELLIS ${ }^{2}$ \\ ${ }^{1}$ Australian Rivers Institute - Griffith University, Australia \\ ${ }^{2}$ Queensland Government Department of Environment and Science, Australia
}

\begin{abstract}
The world heritage listed Great Barrier Reef (GBR) is under threat. After climate change, water quality is recognised as the greatest stress on the reef. Sediment eroded from the catchments is transported into the reef lagoon, contributing to poor water quality. Poor water quality is linked to loss of habitat, coral death, reduced coral recruitment, algal blooms, and Crown of Thorns starfish outbreaks. The Queensland Government, in collaboration with the Australian Government under the joint Reef 2050 Water Quality Improvement Plan, undertakes a regular exercise to report on the health of the GBR and to track progress across a broad range of metrics, including water quality. This exercise comprises a combination of modelling and monitoring activities. Queensland Government periodically review their modelling framework and have identified areas for model improvement. One area identified is how the effects of changed land management practices are modelled. Presently, characteristics of recovery are empirically modelled, however parameterisation is challenged by a sparsity of data. The temporal characteristics of recovery are not presently explicitly accounted for within the modelling process. This study explores the variation in modelled end-of-system sediment loads for an exemplar subcatchment as a result of employing varying temporal signatures of recovery for grazed lands. The purpose of this study is to identify whether the modelled end-of-system sediment loads are sensitive to the time-signature of recovery, to inform how land management practices are included in the models. The results show that the time-signature of recovery can have significant effects on the end-of-system sediment loads where changes in land management practices coincide with local hot-spots of sediment generation. Consideration of the temporal dynamics of erosion reduction due to different intervention strategies is essential to provide the best opportunity to meet water quality targets in the GBR lagoon. Keywords: sediment, catchment, re-vegetation, gully, source, Great Barrier Reef.
\end{abstract}

\section{INTRODUCTION}

The Great Barrier Reef (GBR) is under threat [1], [2]. Climate change is placing unprecedented pressure on the GBR [3], leading to coral bleaching [4] and more severe cyclonic activity [5]. In addition to tackling climate change, other pressures on the GBR need to be reduced, to minimise damage and promote recovery [6], [7]. Avoiding synergistic impacts from multiple stressors is key to preventing rapid decline of reef health, while ensuring greater resilience of the reef to current and future stressors [8].

Sediment and nutrients transported from catchments in the GBR significantly impact water quality and ultimately the health and recovery of the reef [6]. Sediment affects the reef health through a variety of mechanisms. Suspended sediments reduce light availability, which impedes seagrass growth [9], an important habitat and food supply for reef species such as dugong [10]. Reduced light availability also affects the coral's algal symbiont, ultimately

*ORCID: http://orcid.org/0000-0003-4027-9651 
leading to coral death. Sedimentation can bury coral polyps, cause tissue necrosis, and reduce the recruitment and survival of coral larvae [11]. Sediment also assists the transportation of nutrients from the catchments, potentially contributing to eutrophication [12]. High nutrient loads stress vulnerable coral [13], making them more prone to bleaching, and are linked to algal blooms and Crown of Thorns starfish outbreaks [14].

Improving water quality in the GBR lagoon is a joint priority for the Australian and Queensland Governments. Implementation of the Reef 2050 Water Quality Improvement Plan 2017-2022 aims to reduce anthropogenic end-of-catchment loads of fine sediment by $25 \%$, particulate nutrient loads by $20 \%$, and dissolved nitrogen by $60 \%$ [15]. To meet these targets, action is required to reduce sediment erosion and nutrient runoff. The 2017 Scientific Consensus Statement [13] indicates that current activities are insufficient to meet the identified targets.

The next few years will be critical in the fight to save the GBR. In 2015 and 2016 the GBR experienced back-to-back bleaching events. Reducing sediment-linked stressors is critical to allow the reef to recover from previous events. Actions that reduce sediment and nutrient levels in the reef lagoon in the long run may be inadequate to assist the GBR if they do not deliver significant short term benefits.

Gully erosion is a significant component of sediment transported to the GBR [16]. Gully erosion is responsible for $28 \%$ of sediment transported to the GBR World Heritage Area [17], despite occupying a small fraction of the landscape. The remaining sediment is due to hillslope erosion (63\%), and streambank erosion (9\%) [17]. Due to the high contribution of gullies to the total sediment budget, gully remediation and repair has been a focal point for research [18] and investment [19]. While it is known that land use practices such as managing stocking rates will reduce erosion, by reducing land disturbance and allowing ground cover rates to increase and mature trees to establish, what is not well understood is how long it takes for changes in land management practices to translate into observed reductions in the sediment load. As the protection of the GBR is time-critical, it is important to know what the expected benefit of different interventions would be over the short term, not just in the long-term once the full benefits are realised.

The Queensland Government, in collaboration with the Australian Government, undertakes regular modelling exercises to assess the expected outcomes resulting from changed land use and land management practices on the GBR through the P2R (or paddockto-reef) program. The results of this exercise are communicated through the GBR Report Cards, which provides an evaluation of the expected long-term average sediment and nutrient levels within the reef lagoon resulting from current, or projected, land use practices. A longterm average is obtained by modelling sediment and nutrient transport over a 28 -year climate scenario that includes a range of climatic conditions. Although there is considerable uncertainty in these scenarios, this approach nevertheless provides insight into the expected outcomes of changes in land use and land management practices in the long-term. These insights must be evaluated with the understanding that as erosion and nutrient run-off are predominantly rain-driven events, years of low rainfall will yield lower sediment and nutrient levels, while years of high rainfall will yield higher sediment and nutrient levels in the GBR lagoon.

Critically, this modelling approach, focussed on the long-term average, does not consider the temporal trajectory of recovery. That is, the models are applied under the assumption that the full benefits (or losses) due to changes in land use or land management practice have been realised, irrespective of how long it would take for this to occur. This approach is appropriate to the purposes of the GBR Report Cards. It is important to emphasise that implicitly considering temporal changes in environmental performance of the landscape as a function of changing land management practice is not directly relevant to the P2R loads reporting program. The $\mathrm{P} 2 \mathrm{R}$ program reports the average annual constituent load based on 
the status quo landscape management scenario. If however the primary interest were on the short-term impacts or land management practice change, use of the modelling outputs for the GBR Report Cards as the only guide to investment for gully remediation could be problematic as differences between interventions are not explicit in the modelling process, and therefore do not provide an indication of the expected reductions in sediment load in the short term. Although not developed to assess short-term or transitory effects, the models and associated data brought together under the P2R program, appropriately modified, nevertheless provides an opportunity to explore such short-term effects.

While further research is required to identify the specific trajectories of erosion reduction due to different interventions, we can nevertheless investigate the relative effects of temporal variation in sediment reduction due to improved land management practices from a theoretical perspective. Using a grazed catchment in the Burdekin as a case study, we apply different temporal recovery rates to the management factor in the gully erosion equations that represents land management practices (see Section 2.1 for a description of the model) to investigate how this variation affects the end-of-system sediment delivery.

This research demonstrates that the form of the temporal variation assumed is important, with end-of-system delivery dominated by the interaction of the management factor and the rainfall. To obtain a reliable indicator of the short-term benefits of improving land management practices, this research has shown that the temporal trajectory of recovery must be considered.

This paper is organised as follows. The Methods section (Section 2) provides an overview of the modelling framework in Section 2.1 and introduces the case study catchment in Section 2.2. The results are presented in Section 3 together with a discussion in Section 4. A short conclusion is provided in Section 5.

\section{METHODS}

\subsection{Modelling framework and model for gully erosion}

Queensland Government uses the eWater Source [20] platform to model catchment processes for the GBR Report Cards including the processes of sediment erosion, deposition and transport, which are the focus of this analysis. For our analysis we use an instance of the model used for the GBR Report Cards, with modifications to the gully erosion parameters as detailed below. A complete description of the modelling framework for the GBR Report Cards is not provided, but can be found in [21], as we confine our discussion to those aspects of the modelling relevant to our study, namely erosion from gullies. We note however that the eWater Source platform allows for spatial variation in the landscape to be represented in the models. A Functional Unit $(F U)$ approach is employed, where the landscape is divided into units that reflect different land uses, e.g. open grazing or sugar cane. Within each $F U$ a single parameter set is employed, and thus the parameters for each unit represent a summary of the variation within that unit.

The Dynamic SedNet model is used to simulate the supply of sediment to the river system from the erosion of gullies, hillslope and streambanks. For a complete description of the Dynamic SedNet model see [22] and [23]. Erosion from gullies is calculated by relating rainfall driven runoff to the volume of gullies exposed to that runoff, according to eqns (1)-(5). The long-term annual average sediment supply, AASS [t/year] from each $F U$ is given by the product of the total volume of gullies within the functional unit, $V\left[\mathrm{~m}^{3}\right]$, and the soil dry bulk density $P_{s}\left[\mathrm{t} / \mathrm{m}^{3}\right.$ ], divided by the Age [years] of the gully, see eqn (1). The daily sediment load $[\mathrm{kg} /$ day] is calculated by weighting the annual average sediment supply by the ratio of the daily runoff, $Q_{j}(t)$ [mm/day], to the long term average runoff, $Q_{T}$ [mm/year]. The daily sediment load is apportioned into a fine component, DFSL eqn (2), and a coarse component, DCSL eqn (3), using the proportion of fine sediment, $\theta$. Fine sediment is defined 
to be $\leq 20 \mu \mathrm{m}$. The factor 1000 converts the sediment yield from tonnes to $\mathrm{kg}$. We explicitly indicate the temporally varying terms using $(t)$ notation:

$$
\begin{gathered}
A A S S=\frac{P_{s} V}{\mathrm{Age}} \\
\operatorname{DFSL}(t)=1000 A A S S\left(Q_{j}(t) / Q_{T}\right) \theta \\
\operatorname{DCSL}(t)=1000 A A S S\left(Q_{j} / Q_{T}\right)(1-\theta) .
\end{gathered}
$$

The DFSL eqn (2) is further adjusted to account for the impact of land management practices on erosion through the dimensionless management factor $M_{f}^{*}$. Improved land use management practices decrease the daily fine sediment load, $M_{f}^{*}<1$, while poor practices amplify the erosion, $M_{f}^{*}>1$. A further term, the Activity Factor, enables gullies to be switched off when they cease to be productive. As our case study deals only with productive gullies, and therefore Activity Factor $=1$, we neglect this term. Erosion of coarse sediment is assumed to be unaffected by management activities, and therefore is not adjusted from eqn (3). Moreover, as sediment transport within the stream network accounts only for fine sediment, end-of-system sediment loads are determined from the erosion and deposition of fine sediment only. The daily fine sediment yield from gullies for each functional unit that can be transported through the stream network, $S_{F U}^{*}(t)[\mathrm{kg} /$ day $]$ is therefore

$$
S_{F U}^{*}(t)=1000 \frac{P_{s} V \theta M_{f}^{*}}{\operatorname{Age}} \frac{Q_{j}(t)}{Q_{T}} .
$$

The $*$ notation indicates that the daily sediment yield relates to a time-invariant management factor. As detailed information about the year of gully initiation is not known, it is assumed that gully initiation coincided with the commencement of intensive grazing, and that Age = 100 for all functional units within the case study.

Eqn (4) calculates the daily fine sediment yield from gullies within a functional unit as a function of the daily runoff, soil characteristics, gully volume and age, modified by the management factor to account for the effects of land management practices on the realised erosion. Land management practices captured through $M_{f}^{*}$ include stocking rates, re-vegetation of degraded land, and engineering solutions such as rock capping gully heads, or the installation of porous check dams. Engineering solutions that effectively eradicate the gully are better captured through the reduction in the gully volume parameter, $V$, such solutions are not considered in this analysis.

To investigate the effects of temporal variation in sediment reduction resulting from improvements to land management practices, we modify eqn (4) to introduce a timedependency in the management factor $M_{f}^{*}$. As the rate of sediment reduction due to different land management practices is not currently known, we explore the effects of temporal variation in the reduction by considering some exemplar rates. We update eqn (4) to reflect a time-varying management factor, $M_{f}(t)$. Thus the daily sediment yield calculated with a time-dependent management factor, $S_{F U}(t)[\mathrm{kg} /$ day], is given by

$$
S_{F U}(t)=1000 \frac{P_{s} V \theta M_{f}(t)}{\text { Age }} \frac{Q_{j}(t)}{Q_{T}} .
$$

The GBR Report Cards consider four classes of land management practice, rated D to A, and relate these classes to the management factor according to Table 1 . The 2016 Report Card indicates that 25\% (7599458 ha) of gully area was managed under best management practice systems, that is A-Class. Incorporating pastures and streambanks, 36\% of grazing 
Table 1: Relative gully erosion rate by management practice class for grazed land, adapted from [25, Table 11] (originally adapted from [26, Table 4]). [25] define land management practices for grazing under the $\mathrm{ABCD}$ framework as A (highly likely to maintain land in good condition), B (likely to maintain land in good/fair condition), C (likely to degrade some land), and D (highly likely to degrade land to poor condition).

\begin{tabular}{|l|c|c|c|c|}
\hline Grazing practice management class & A & B & C & D \\
\hline Management factor $M_{f}^{*}$ & 0.75 & 0.9 & 1 & 1.25 \\
\hline
\end{tabular}

lands in the GBR catchments were managed under best practice, requiring considerable improvement to reach the 2018 target of $90 \%$ of grazing lands managed in accordance with A-class practices [24].

To explore the effect of a time-varying management factor on end-of-system delivery we consider four different rates of erosion reduction under six timeframes for recovery, a total of 24 scenarios. In all cases we assume that the simulation commences with gully erosion in accordance with C-class management, that is $M_{f}(0)=1$, and by the end of the 28 year simulation period $90 \%$ of gully area has achieved the erosion reductions associated with Aclass management, that is $M_{f}\left(t_{\text {final }}\right)=M_{f}^{\dagger}=0.775$. We consider four different rates of improvement, a step function that shows no benefit until the year of full benefit is reached, as well as linear, quadratic and exponential declines in erosion. The six different timeframes correspond to increasing time required for the full benefits of management practice change to be achieved. This analysis compares recovery periods of $\tau=2,5,10,15,20$ and 25 years. These are compared with the baseline case of full benefit achieved throughout the simulation, that is $M_{f}(t)=0.775$. Refer to Table 2 for the equations used to form the time-dependent management functions $M_{f}(t)$. Fig. 1 shows the form of the management factor time series for three of the recovery periods considered together with the baseline case. The management factor is updated annually, at the start of each simulation year (1 July), therefore within each simulation year the management factor is held constant. The 28-year simulation period is 1 July 1986 to 30 June 2014, which includes a variety of weather events including periods of high and low rainfall. We note that neither this analysis, nor the P2R program, seeks to model historical loads associated with this time period.

\subsection{Study site}

The Bowen catchment is located within the greater Burdekin catchment, a $146,000 \mathrm{~km}^{2}$ area that drains into the GBR south of Townsville in far north Queensland, as shown in Fig. 2. The Burdekin catchment is the largest source of contemporary sediment to the GBR lagoon [27]. The Burdekin catchment is dominated by grazing, which occupies $91 \%$ of the region [27], and has been linked to vegetation clearing and an acceleration in sediment supply to the GBR. Cattle numbers have increased from $<0.05$ million in 1860 to 1.3 million in 2016-17 [28]. The Bowen catchment occupies $7 \%$ of the Burdekin catchment and discharges below the Burdekin Falls Dam. An estimated $94.7 \%$ of sediment reaching the headwaters of the Bowen catchment will be discharged into the GBR lagoon.

\section{RESULTS}

The effects of varying the gully management factor on the end-of-system delivery of fine sediment are shown in Figs 3-5. The results are presented as excess sediment delivered to 
Table 2: Equations for the annual management factor $M_{f}(t)$ during the recovery period for each of our studies, where $t=\tau$ is the year in which the full benefits of changed land practices are achieved, $M_{f}(0)$ is the initial management factor at the start of the simulation period and $M_{f}^{\dagger}$ is the final management factor achieved due to changed land practices. Once the full benefits of recovery are achieved $M_{f}(t)=M_{f}^{\dagger}, t>\tau$.

\begin{tabular}{|ll|}
\hline Recovery form & Management factor $\boldsymbol{M}_{\boldsymbol{f}}(\boldsymbol{t})$ \\
\hline Step & $M_{f}(0) \quad t \leq \tau$ \\
\hline Linear & $\frac{M_{f}^{\dagger}-M_{f}(0)}{\tau} t+M_{f}(0) \quad t \leq \tau$ \\
\hline Quadratic & $\frac{M_{f}^{\dagger}-M_{f}(0)}{\tau^{2}} t^{2}+M_{f}(0) \quad t \leq \tau$ \\
\hline Exponential & {$\left[M_{f}^{\dagger}-M_{f}(0)\right]\left[\frac{\exp (-0.25 t)-1}{\exp (-0.25 \tau)-1}\right]+M_{f}(0) \quad t \leq \tau$.} \\
\hline
\end{tabular}

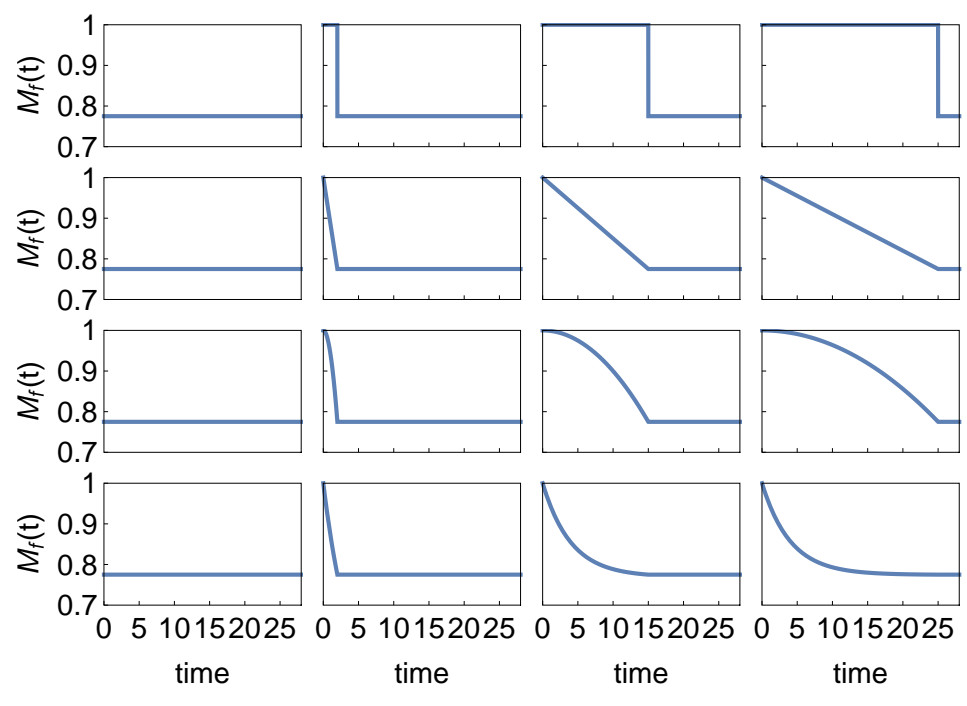

Figure 1: Exemplar time-dependent management factor, $M_{f}(t)$, values used for this analysis. Each column represents a different recovery period. The baseline case of instantaneous recovery is shown in column 1, column 2 corresponds to a 2-year recovery period, column 3 to a 15-year recovery period, with column 4 being a 25-year recovery period. The analysis also considers recovery periods of 10 and 20 years. The rows correspond to the four assumed rates of recovery, namely step, linear, quadratic and exponential. Refer to Table 2 for the corresponding equations. 


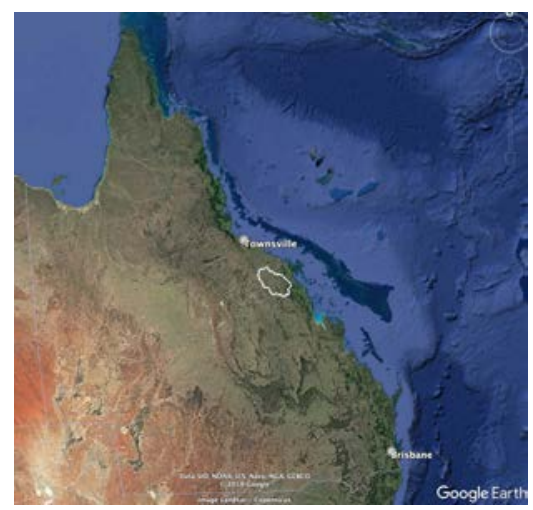

Figure 2: Location of the Bowen catchment in the state of Queensland.

the GBR lagoon, we refer to this as the delivered excess sediment. The delivered excess sediment is calculated by scaling the original sediment load, in kilotonnes [kt], by the River System Delivery Ratio, and subtracting the baseline comparison case. The River System Delivery Ratio represents the proportion of sediment from a catchment that will be delivered to the GBR lagoon. Unless a catchment discharges directly into the lagoon, some of the fine sediment discharged from a catchment will be deposited before reaching the lagoon. Previous analysis has identified the River System Delivery Ratio for the Bowen catchment to be 0.947113 . The baseline comparison case, which reflects immediate full benefits from $90 \%$ of grazing lands managed by A-class practices, is subtracted from the sediment load to better illustrate the effect of improved land use management practices being delayed. Once a scenario achieves the full benefits of recovery, that is $M_{f}(t)=0.775$, the sediment load will be equal to that of the baseline case, and the excess sediment goes to zero.

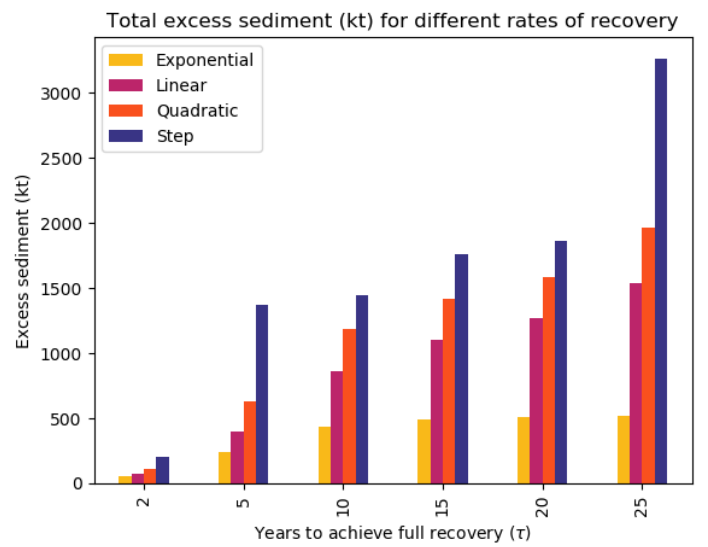

Figure 3: Sum of the excess sediment exported to the GBR lagoon over the 28-year simulation for the 24 assumed management factor time-series, grouped by the recovery period. 


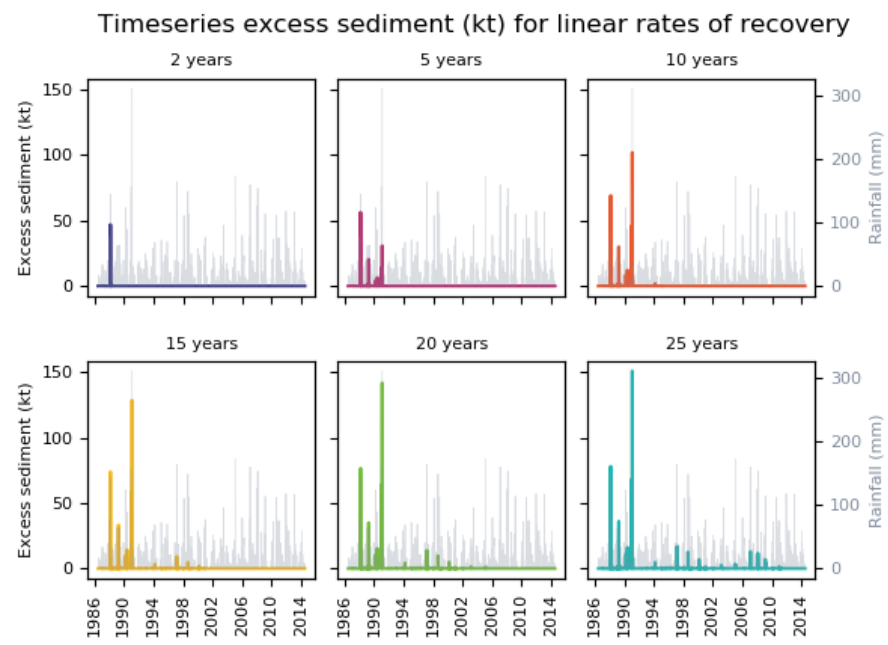

Figure 4: Timeseries of excess sediment [kilotonnes] delivered to the GBR lagoon under linear recovery regimes for the six different $\tau$ scenarios. Daily rainfall $[\mathrm{mm}]$ is provided for reference.

As detailed in Section 2, a 28-year simulation period is employed for all simulations, using historical weather observations from 1 July 1986 to 30 June 2014. The total delivered excess sediment over the simulation period for the 24 scenarios is shown in Fig. 3.

The time series of delivered excess sediment for the 6 recovery periods with a linear recovery form is shown in Fig. 4. The cumulative delivered excess sediment for the 24 scenarios is shown in Fig. 5. Fig. 5(a) arranges this data by the rate of recovery, while Fig. 5(b) shows this same data arranged by the recovery period. Daily rainfall [mm] from Bureau of Meteorology station 33176 (Gatton Vale), located within the Bowen catchment, is shown for reference in Figs 5 and 4, as gully erosion varies significantly between wet and dry seasons.

\section{DISCUSSION}

This analysis indicates that the assumed form of recovery due to improved land use management practices significantly affects the modelled sediment load delivered to the GBR lagoon. Both the rate of recovery (step, linear, quadratic or exponential) and the timeframe to achieve the full benefits of recovery (indicated by the recovery period $\tau$ ) are shown to be important. Across the full 28-year simulation, shifting $90 \%$ of grazing lands from C-class to A-class management results in a $12.4 \%$ reduction in fine sediment reaching the GBR lagoon. In comparison, a delay of 5 years before seeing any benefits from improved practices decreases this benefit to no more than $7.5 \%$ (as modelled by the step function). To place this in perspective, $60 \%$ compliance with A-class practices throughout the simulation $\left(M_{f}(t)=\right.$ 0.85 ) corresponds to an $8.3 \%$ reduction in total exported fine sediment. Therefore a 5 year delay in achieving erosion reduction is equivalent across the simulation period to missing the target for area of land managed according to A-class practices by more than a third. A delay in the reduction in erosion following improved practices of this order is not infeasible. While there is a lack of published research on the temporal evolution of erosion reduction following natural regeneration or revegetation of grazing lands, in a different context [29] found dense 
Cumulative excess sediment (kt) for different rates of recovery
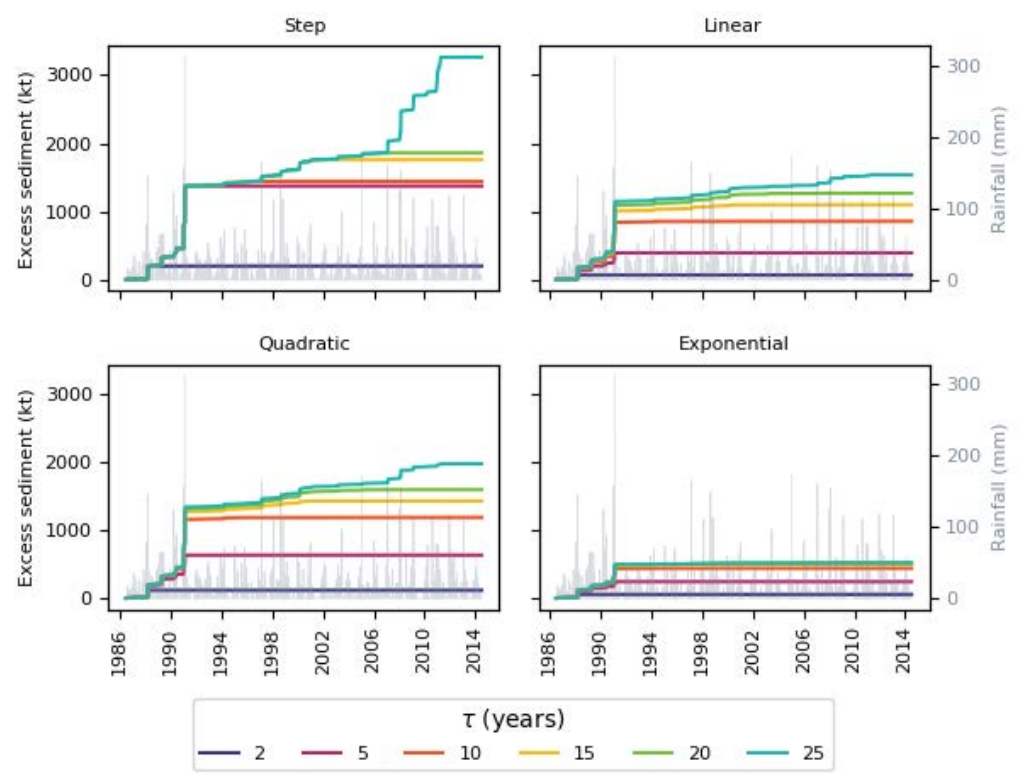

(a)

\section{Cumulative excess sediment ( $\mathrm{kt}$ ) for different rates of recovery}
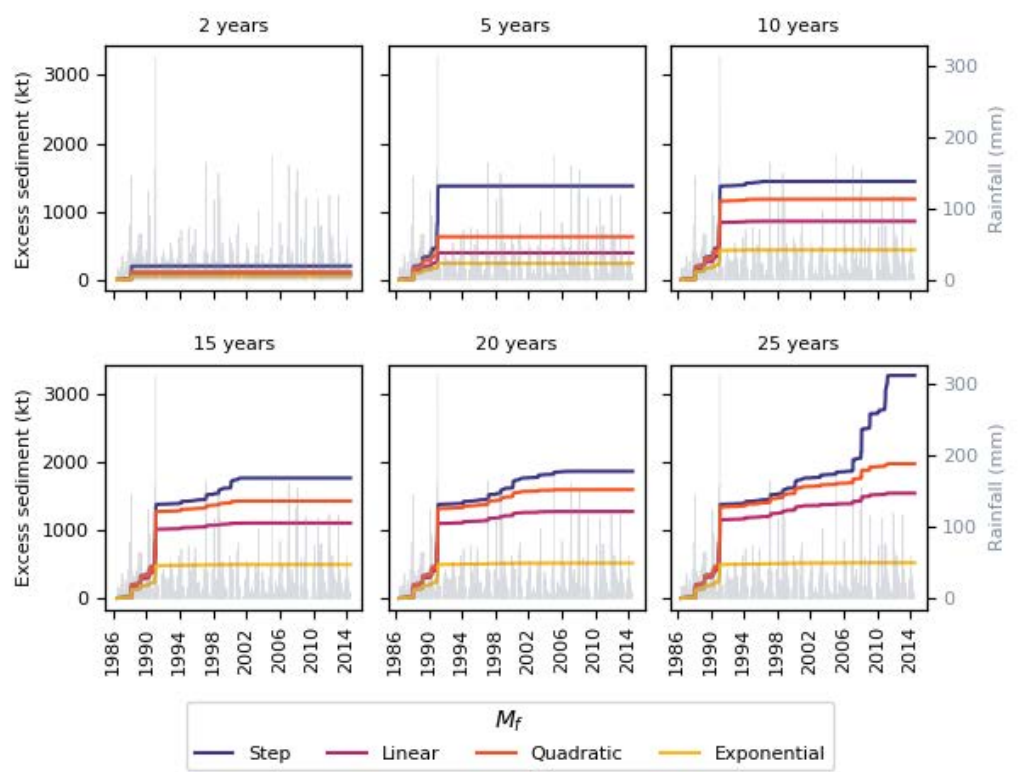

(b)

Figure 5: Cumulative excess sediment [kilotonnes] delivered to the GBR lagoon for the 24 assumed management factor time-series. The upper plot (a) groups the results by the form of recovery, while the lower plot (b) groups the same results by recovery period. Daily rainfall $[\mathrm{mm}]$ is provided for reference. 
canopies typically required 10 years to develop following revegetation, illustrating the time lag between management action and environmental benefits.

The excess sediment delivered to the GBR under the different scenarios is not uniform in time. Gully erosion is a rainfall driven event, and therefore natural variation in the rainfall will result in variation in erosion. Furthermore, our analysis considers temporal variation in the rate of erosion as a model for delays in the benefits of management action. The impact of sediment on the GBR cannot be reduced to a consideration of average sediment loads at the entry to the lagoon. Different organisms within the GBR will have individual tolerance thresholds for both the length and quantity of exposure. We must therefore consider the temporal trajectory of delivered sediment when evaluating the impact of changed land management practices on the GBR. While it is beyond the scope of this paper to link our catchment models to impacts on the GBR, we nevertheless explore how the rate of recovery potentially impacts the GBR. Fig. 4 shows the temporal trajectory of delivered excess sediment for the 6 scenarios with a linear recovery form. Excess sediment is displayed to better show differences between the recovery periods, peak events correspond to the high rainfall events shown. As expected, the magnitude of peak events is greater the longer the recovery period. It is therefore likely that throughout the recovery period acute stresses from peak erosion events will be further amplified due to the delay between management action and the benefits of reduced erosion. Comparable results were obtained for the step and quadratic forms, however the amplification of peak events under the exponential form was considerably reduced after approximately 10 years. This is due to the similarities in the exponential functions for $M_{f}(t)$ with $\tau \geq 10$, as shown in Fig. 1 .

Variation in the excess sediment loads is driven by the intersection of the gully management factor and the rainfall. The impact of this intersection is well illustrated by the large rainfall events in April 1991. Occurring towards the end of year 5, this event has no effect on the excess sediment in the $\tau=2$-year simulations (see Fig. $5 b$ ), as once the full benefits of improved practices are realised, $t>\tau$, the excess sediment exported to the lagoon is zero. In comparison, the $\tau=5$-year simulations show significant differences between the different recovery forms. The exponential form, being close in value to the long-term objective of $M_{f}(t)=0.775$, sees minimal impact from this large rainfall event, whereas the step function experiences a more than 5-fold increase in excess sediment over a short period of time. In contrast, the next 5-year period has relatively low rainfall resulting in modest increases in excess sediment for the step function simulations, as shown by comparing the 5 (pink) and 10 (orange) year lines for the step profile in Fig. 5(a). As erosion is rain-driven, variations in rainfall will lead to natural variation in erosion. Therefore, obtaining a realistic estimate of the temporal trajectory of fine sediment supply following remediation actions requires consideration of climate variation.

It is expected that different interventions will have potentially vastly different rates of recovery. These differences need to be considered when evaluating different intervention strategies. If a period of low rainfall follows intervention, the benefits to the GBR between different approaches may well be similar. However, as shown in Figs 4 and 5, where a period of high rainfall occurs soon after intervention, different approaches, and hence recovery rates, will result in markedly different sediment loads entering the GBR lagoon. This has the potential to result in significantly different outcomes for the affected areas of the GBR. Further research is required to identify which recovery rates are representative of different approaches, and the expected impacts on the GBR.

\section{CONCLUSION}

Reducing sediment-linked stressors on the GBR is essential to enable damaged reefs to recover and to promote resilience to climate change. These improvements are required in the short-term, therefore it is imperative that the temporal trajectory of recovery is considered 
when evaluating the expected benefits of different interventions to reduce erosion. A lag between gully remediation activities and achieving reduction in erosion is not unexpected, particularly for management actions such as reducing stocking rates, fencing disturbed land, and revegetation projects.

The modelling framework, and associated data, developed for the P2R program provides an opportunity to explore the potential effects of such a time lag through a simple modification to the gully management factor within the equation for gully erosion. This paper presents a theoretical investigation into the variation in fine sediment loads delivered to the GBR lagoon from a case study catchment due to delays in achieving erosion reduction from improved management practices. We demonstrate that both the rate of recovery and the recovery period, that is until full benefits of improved practices are achieved, significantly affects the load of sediment reaching the GBR lagoon. Consequently, evaluation of different intervention activities and targets requires knowledge of the temporal trajectory of recovery. Failure to consider the temporal trajectory of recovery could lead to remediation actions being identified that are insufficient to meet objectives for water quality.

Research is required to identify the appropriate recovery trajectories for different interventions. In the mean time the methods presented in this study, together with expert knowledge, may be used to form indicators of the likely sediment loads over time.

\section{ACKNOWLEDGEMENT}

This project has received funding support from the Queensland Government through the Queensland Water Modelling Network.

\section{REFERENCES}

[1] Hughes, T.P., Climate change, human impacts, and the resilience of coral reefs. Science, 301(5635), pp. 929-933, Aug. 2003.

[2] Lewis, S.E. et al., Herbicides: A new threat to the Great Barrier Reef. Environmental Pollution, 157(8-9), pp. 2470-2484, Aug. 2009.

[3] Hoegh-Guldberg, O. et al., Coral reefs under rapid climate change and ocean acidification. Science, 318, pp. 1-7, Dec. 2007.

[4] Hoegh-Guldberg, O., Climate change, coral bleaching and the future of the world's coral reefs. Marine and Freshwater Research, 50(8), pp. 839-29, 1999.

[5] Walsh, K.J.E. \& Ryan, B.F., Tropical cyclone intensity increase near Australia as a result of climate change. Journal of Climate, 13, pp. 3029-3036, Aug. 2000.

[6] Great Barrier Reef Marine Park Authority, Great Barrier Reef Outlook Report 2014, Tech. Rep., Jul. 2014.

[7] De'ath, G., Fabricius, K.E., Sweatman, H. \& Puotinen, M., The 27-year decline of coral cover on the Great Barrier Reef and its causes. Proceedings of the National Academy of Sciences, 109(44), pp. 17995-17999, Oct. 2012.

[8] Pandolfi, J.M., Connolly, S.R., Marshall, D.J. \& Cohen, A.L., Projecting coral reef futures under global warming and ocean acidification. Science, 333, pp. 1-6, 2011.

[9] Wooldridge, S.A., Preventable fine sediment export from the Burdekin River catchment reduces coastal seagrass abundance and increases dugong mortality within the Townsville region of the Great Barrier Reef, Australia. Marine Pollution Bulletin, 114(2), pp. 671-678, Jan. 2017.

[10] Preen, A. \& Marsh, H., Response of dugongs to large-scale loss of seagrass. Wildlife Research, 22(4), pp. 507-514, 1995.

[11] Rogers, C.S., Responses of coral reefs and reef organisms to sedimentation. Marine Ecology Progress Series, 62, pp. 185-202, 1990. 
[12] Garzon-Garcia, A., Burton, J., Franklin, H.M., Moody, P.W., De Hayr, R.W. \& Burford, M.A., Indicators of phytoplankton response to particulate nutrient bioavailability in fresh and marine waters of the Great Barrier Reef. Science of the Total Environment, 636, pp. 1-12, Sep. 2018.

[13] Waterhouse, J. et al., 2017 Scientific Consensus Statement. Tech. Rep., State of Queensland, Aug. 2017.

[14] Brodie, J. et al., Synthesis of evidence to support the Scientific Consensus Statement on Water Quality in the Great Barrier Reef. Tech. Rep., State of Queensland, 2008.

[15] Eberhard, R. et al., Management options and their effectiveness. Scientific Consensus Statement 2017, Chapter 4, pp. 1-174, 2017.

[16] Bartley, R. et al., Sources of sediment, nutrients, pesticides and other pollutants to the Great Barrier Reef. Scientific Consensus Statement 2017, Chapter 2, pp. 1-105, 2017.

[17] McKergow, L.A., Prosser, I.P., Hughes, A.O. \& Brodie, J., Sources of sediment to the Great Barrier Reef World Heritage Area. Marine Pollution Bulletin, 51(1-4), pp. 200211, Jan. 2005.

[18] Program, N.E.S., Project 3.1.7 reducing sediment loads to the great barrier reef: developing optimal approaches for treating alluvial gully erosion, https://nesptropical. edu.au/index.php/round-3-projects/project-3-1-7/. Accessed on: 18 Dec. 2018.

[19] Queensland Government, Great Barrier Reef Innovation Fund.

[20] eWater Source, https://ewater.org.au/products/ewater-source/.

[21] Australian and Queensland Governments, Paddock to Reef Integrated Monitoring, Modelling and Reporting Program. Tech. Rep., Nov. 2018.

[22] Ellis, R., Dynamic SedNet component model reference guide. Department of Science, Information Technology, Innovation and the Arts. State of Queensland, Tech. Rep., 2015.

[23] Wilkinson, S.N., Dougall, C., Kinsey-Henderson, A.E., Searle, R.D., Ellis, R.J. \& Bartley, R., Development of a time-stepping sediment budget model for assessing land use impacts in large river basins. Science of the Total Environment, 468-469(C), pp. 1210-1224, Jan. 2014.

[24] Australian and Queensland Governments, Great Barrier Reef Report Card 2016 Results - Reef Water Quality Protection Plan, pp. 1-155, 2017.

[25] Waters, D.K. et al., Modelling reductions of pollutant loads due to improved management practices in the great barrier reef catchments - whole of GBR. Queensland Department of Natural Resources and Mines, Toowoomba, Queensland, Tech. Rep., 2014.

[26] Thorburn, P.J. \& Wilkinson, S.N., Conceptual frameworks for estimating the water quality benefits of improved agricultural management practices in large catchments. Agriculture, Ecosystems and Environment, 180, pp. 192-209, Nov. 2013.

[27] Bartley, R., Croke, J., Bainbridge, Z.T., Austin, J.M. \& Kuhnert, P.M., Combining contemporary and long-term erosion rates to target erosion hot-spots in the Great Barrier Reef, Australia. Biochemical Pharmacology, 10(C), pp. 1-12, Jun. 2015.

[28] Australian Bureau of Statistics, 7121.0 Agricultural Commodities, Australia and state/territory and NRM regions, 2016-17. Excel spreadsheet, cat. no. 71210DO002_201617, 5 2018, http://www.abs.gov.au/AUSSTATS/abs@.nsf/ DetailsPage/7121.02016-17?OpenDocument.

[29] Vesk, P.A., Nolan, R., Thomson, J.R., Dorrough, J.W. \& Nally, R.M., Time lags in provision of habitat resources through revegetation. Biological Conservation, 141(1), pp. 174-186, Jan. 2008. 